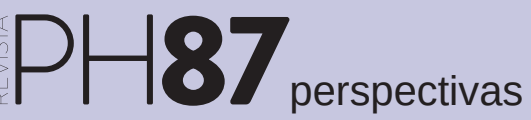

a debate Preexistencias en la ciudad histórica contemporánea: viabilidad y convivencia

| coordinan Plácido González Martínez, Miguel Ángel Tabales Rodríguez

\title{
La difusión del patrimonio. Una obligación social
}

\author{
Álvaro Álvarez Gutiérrez | Escuela Técnica Superior de Arquitectura, Universidad Politécnica de Madrid
}

URL de la contribución <www.iaph.es/revistaph/index.php/revistaph/article/view/3561>

La labor investigadora del patrimonio parece estar en posesión de especialistas doctos en la materia, cuya labor no siempre ve la luz por falta de financiación o apoyo institucional hecho; por ende, perjudicial para el conocimiento colectivo.

Atendiendo al ámbito internacional, las cartas y recomendaciones internacionales por parte de UNESCO e ICOMOS abogan por la conjunción íntegra entre sociedad y patrimonio. El patrimonio, grosso modo, es reconocido como la muestra de una serie de valores y testimonio histórico de un pueblo, un patrimonio común para cuya salvaguarda las generaciones futuras se reconocerán responsables solidarias. Su protección y desarrollo dependerán si es apreciado y asumido por el público y en particular por la generación más joven.

Cuando las medidas de preservación se toman a partir de modelos y conceptos externos, sin atender el modo de vida ni la cultura, se corre el riesgo del rechazo local, suponiendo la destrucción del patrimonio. El éxito de cualquier gestión en política de conservación depende de tomar en consideración los factores sociales, es decir, la integración del patrimonio con la vida social fortaleciendo la cooperación y el compromiso de las comunidades locales para desarrollar estrategias sostenibles de conservación, gestión y difusión del patrimonio.

En el ámbito nacional, la propia Constitución española en su artículo 46 argumenta la necesidad de proteger el patrimonio histórico, cultural y artístico como medio de progreso social y desarrollo económico del país. Dicha posición viene refrendada por la Ley de patrimonio de 1985 al entender que los bienes deben estar al servicio de la colectividad, en el convencimiento de que con su disfrute se facilita el acceso a la cultura y que ésta, en definitiva, es camino seguro hacia la libertad de los pueblos y apunta a la Administración del Estado para el establecimiento de medidas con los restantes poderes públicos con el fin promover el enriquecimiento, fomentar y tutelar el acceso de todos los ciudadanos a los bienes comprendidos en él. Por todo ello, la Ley de patrimonio histórico español justifica que todas las medidas sólo cobran sentido si, al final, conducen a que un número cada vez mayor de ciudadanos puedan contemplar y disfrutar las obras que son herencia de la capacidad colectiva de un pueblo. ¿Cómo ha de responder la normativa estatal y autonómica para lograr dicho objetivo? fomentando figuras de difusión de corte realista dejando atrás la mera declaración de intenciones y los meros formalismos de acceso al patrimonio sin un papel activo en su divulgación.

La modificación del sistema de difusión del patrimonio debe partir de la modificación de la legislación en materia urbanística y patrimonial. Actualmente, la norma urbanística convive con las leyes especiales de patrimonio histórico legitimizada por cada autonomía y, paradójicamente, es aquella y no esta quien contiene la regulación más detallada y presumiblemente más protectora para el bien histórico. Parece, en suma, el momento de tomar conciencia de esta situación y de arbitrar las medidas necesarias para que los conflictos no se produzcan, lo cual es relativamente simple. Puesto que urbanismo y patrimonio están íntegramente ligados, la generación de una ley común marcaría un desarrollo progresivo tanto en la protección como el conocimiento patrimonial, considerado como común aquello que los expertos en su afán de clasificar han denominado derecho especial. En este sentido ya se han acometido acciones similares, por ejemplo, en la Ley 4/2009 de protección ambiental integrada, de 14 de mayo. La ley debe incluir figuras concretas, específicas y detalladas para la protección $y$, especialmente, la divulgación del patrimonio, tanto si afecta al sector privado como público. Y con mayor consideración en el patrimonio arqueológico, dictami- 


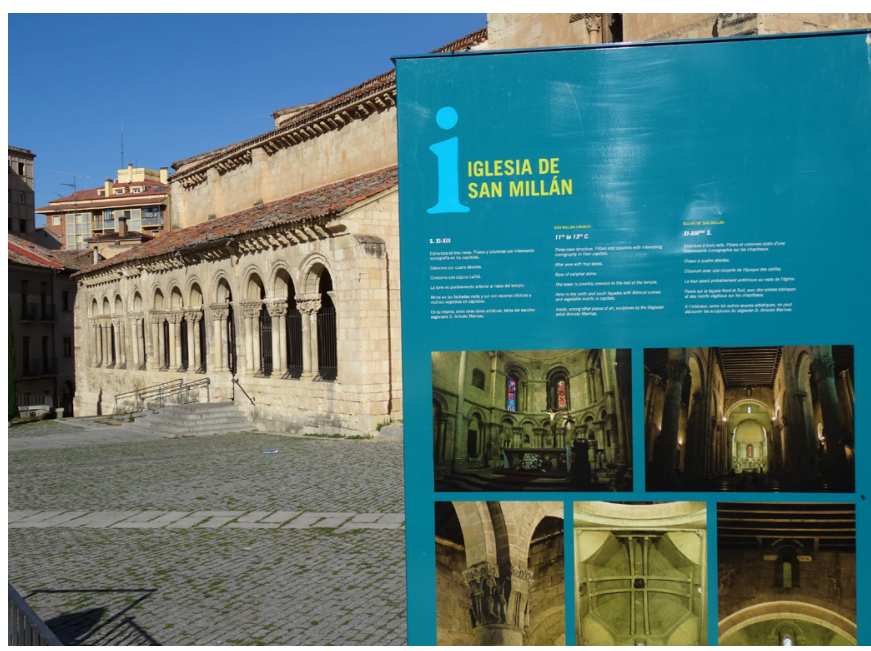

Panel informativo de la iglesa de San Millán (Segovia) | foto Martín J. Fernández Muñoz

nado por ley como dominio público. ¿Dónde está la participación ciudadana en los procesos de generación del nuevo planeamiento, la colaboración en los procesos de investigación fruto de inversiones tanto públicas como privadas?

Tal vez, la propia normativa legislativa debe establecer las directrices y la voluntad forzada de instituir órganos de gestión para la difusión del patrimonio. Un ejemplo apropiado es el Plan Especial de las Áreas Históricas de Segovia (PEAHIS), en fase de aprobación inicial, donde se estima oportuno en su redacción la disposición de órganos de gestión del patrimonio arqueológico, entre cuyos fines se encuentra la participación activa de la ciudadanía de los resultados obtenidos en cada actuación arqueológica haciéndola accesible y difundiéndolo al considerar que el patrimonio arqueológico es de dominio público y, por ende, fuente de conocimiento y difusión.

Ante la doctrina de obligar a las empresas privadas a realizar excavaciones arqueológicas sin voluntad de mostrar los resultados, parece trascendental apoyar políticas para la investigación del patrimonio a través de la Universidad. La política educacional debe encararse a plantear un proceso educacional cuya ejecución y resultado sea de aplicación a la vida real. Cierto es, ante la

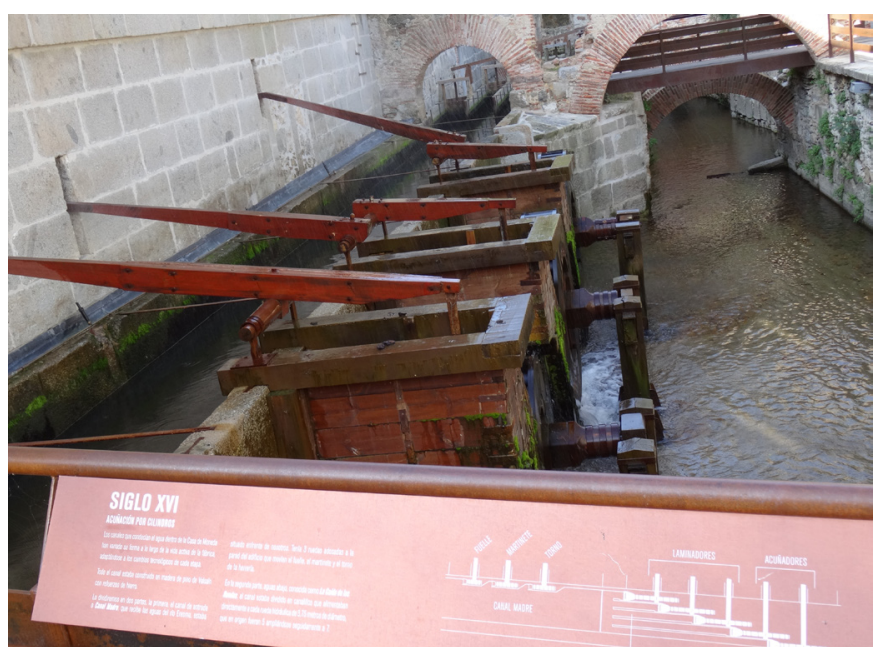

Musealización en la Real Casa de la Moneda, en Segovia | foto Martín J. Fernández Muñoz

débil situación económica del país, el apoyo al desarrollo tecnológico más puntero, pero adquiere mayor carácter el conocimiento del pasado apelando a consideraciones científicas, revelando nuevos aspectos y forjando la identidad local de cada zona. No hay que olvidar el potencial patrimonial del país en aras de financiar otros desarrollos. Sólo un conocimiento exhaustivo de nuestro pasado permitirá embaucar a la población de manera conjunta en su futuro.

Para finalizar, la difusión del patrimonio constituye una obligación transcendental por parte las autoridades competentes, cuya ejecución no parta de meras formalidades, sino de regulaciones legislativas que impliquen el cumplimiento de las recomendaciones de UNESCO, de las cuales nos enorgullece formar parte. Es en esta escala donde verdaderamente han de concentrarse los esfuerzos, puesto que la difusión del patrimonio y su protección no solo repercute en la propia población, considerada como máxima beneficiaria, sino que también repercute en el enriquecimiento del patrimonio cultural mundial. 